\title{
Seeing both sides: A student's experience of dual roles in a university co-creation project
}

David Beevers, School of Health and Society, University of Salford, UK.

Contact: d.beevers@edu.salford.ac.uk

Increased importance has been attached to academic co-creational initiatives where students become involved with staff in shaping future curriculum design. Between

September 2019 and August 2020, as an undergraduate student at the University of Salford, I was fortunate enough to experience two roles in a co-creation initiative: firstly as a project co-designer and later as a student participant in the process I had helped to create. The overall aim of the project was to redesign the cognitive psychology modules on the undergraduate psychology degree courses using feedback on current methods from students gathered at a series of ideation workshops. The project targeted an apparent reluctance among students to take up cognitive psychology when choosing module options. The two roles which I was able to perform were: (1) assisting in the design of the project and the ultimate redesign of the modules, which would involve delivery of workshops to allow students to share and debate their ideas of how to develop cognitive psychology at the university; and (2) participating in the workshops and putting forward my own ideas about the development of the modules alongside other students. Therefore, I was able to see both sides of the process.

Involving students in this process of redesigning courses or modules is deemed to be of value to both students and staff. Students learn, giving them a degree of autonomy and a sense of ownership of (and some control over) their education. Additionally, staff, who have perhaps become used to a tried-and-tested, traditional teacher-centred pedagogy find student input can inspire fresh ways of approaching teaching. In this article, I explore my experience in these two roles. I also reflect on my frustration at the limited number of students who came forward to take part in the process.

\section{MY EXPERIENCE ON THE PROJECT DESIGN TEAM}

I was approached by the leader of the project (a senior lecturer in psychology) to take part because of my involvement in previous cognitive research projects. When the project began, I was in my second year at the University of Salford in the UK, studying psychology and counselling. I was one of two students on the project team with six members of staff making up the other team members. There were five staff who teach on the cognitive psychology modules and one other member of staff from outside the cognitive psychology team. The other student on the project team was in the final year of her degree course. Staff who taught on the cognitive modules had raised concerns over the lack of student engagement with cognitive psychology. The project aimed to address this lack of engagement by assessing and potentially redesigning the modules. When I was asked to join the team, I did not hesitate to accept. This was an unmissable opportunity to gain 
experience of a curriculum design process. At this early stage of enthusiastically accepting the invitation, the fact that I had no discernible experience to draw on did not deter me. Concern over my novice status would come later.

I saw being part of the project team as an opportunity for me to move from being simply a learner, albeit an active and enthusiastic one, to an agent of change involved in decision-making related to delivering learning to students in the future. It was at the first project meeting that I had to deal with the issue of feeling inhibited, surrounded by people with so much academic experience of delivering learning. I felt that I urgently needed to find my feet as the sooner I felt comfortable in the role and confident enough to contribute, the sooner I would justify my involvement, both to the rest of the team and myself. The question, "Why am I here?", kept popping into my head. However, I decided to reframe this and instead thought: "Why have I been asked?" Something had made the others on the team encourage me to get involved. This reframing of my thinking shifted my mindset to appreciate that my specific student perspective was going to be valued. Co-creation, I was to realise, is dependent on a variety of perspectives being embraced. It was important that everyone brought different skills and views. If team members all bring the same skill set, creativity will suffer. However, with various different perspectives taken into account, novel outcomes are possible. This made me appreciate that I could be a useful addition to the process.

After completing the project I discovered a model from Bridges (2004) which accurately reflected my experience on the project. Bridges describes the transition to new experiences as having three stages: (1) an ending of the prior state of not experiencing; (2) a neutral zone, or limbo, where the new experience has begun but there is still a sense of being out of one's depth; and (3) new beginnings, where an understanding of place and purpose is achieved. I can now see that my involvement in the project was aligned to these three stages.

\section{The end of not experiencing}

This first stage existed for me between the invitation to join the team and the first team meeting. I did not at that stage know what was expected of me or what contribution I could make; what I did know for sure was that I had ended my experience of being "just a student." I had begun to experience being a project team member, and was now in a position to start experiencing more than being just a student. I was immediately learning by watching how staff on the project approached curriculum design and I was able to learn new skills as a result of tapping into their experience. I could now view my educational experience from a different, added perspective.

\section{Navigating the neutral zone}

The first project team meeting marked the beginning of my spell in Bridges's neutral zone, that area of limbo where, at the outset, I very much felt myself to be the novice in the team. I was reminded of my early experiences in the first year when I questioned my aptitude for the degree course. Everyone else seemed so much more aware and familiar with the task ahead. This sense of imposter syndrome, or being out of my depth, led to me assuming I would be reluctant to contribute. However, as the first meeting progressed, staff made it clear I would be treated as an equal. All members of the team were asked for their suggestions and views, and I felt the same level of attention and discussion was awarded to my contributions as to those of other members. My confidence grew. Very quickly I found 
myself happily speaking up. The neutral stage had not lasted long at all, which in my eyes reflected the inclusivity of the project team and my commitment to the project.

\section{The reward of new beginnings}

The stage of new beginnings heralds not just the start of a novel experience but also represents the reward for having the desire for self-improvement. Now, armed with the new-found confidence gained from my ideas being appraised equally, I could look forward to the opportunities that would result from being part of the project team. I even felt proud of myself: by accepting a place on the project, I had trusted in my ability to overcome inevitable initial feelings of inexperience. I was now in a position to fully immerse myself in the process of workshop design and delivery. I put forward ideas and suggestions without hesitation, and these were taken on board by the rest of the team. Discovering Bridges's model as I began to reflect on my participation in the project made me understand this stage of my progress as part of the team. It was during this stage that I found my attitude changing from one of self-conscious reluctance to contribute to a realisation that my opinions were valued.

\section{A sense of frustration}

The team leader envisaged a series of three-hour workshops designed to allow students to be consulted on their suggestions for ways the modules could be made more engaging in the future. The team leader asked members for their availability to either facilitate or assist at the workshops. Roles were then assigned with all members involved in the final decision about who was to lead and assist in the workshops. I put myself forward to both lead some and assist at others. However, the unexpectedly low number of students signing up to take part led to a re-adjustment in the timetabling, and I was only able to assist on two occasions. I was frustrated not to get the chance to lead; my disappointment was a measure of how far my confidence had grown, due in no small part to the personal support and encouragement from the other team members.

From the beginning, I appreciated that the project marked a generous move on the part of the staff on the project, who were happy to relinquish a degree of control in pursuit of new ways of improving the student experience. A literature search after my involvement with the team highlighted this is not a universal view. Some staff are reluctant to engage with students in a co-creative process because they see no value in it, given students' lack of pedagogical experience (Murphy et al., 2017). This lack of experience reminded me of doubts about my own credentials for joining the project team in the beginning. Yet when staff are reluctant to share their workload due to perceived student inexperience, they misconstrue the purpose of involving students. My involvement in both roles is valuable because it brings something different to the process. Students are consulted for their additional insight based on their experiences as a student, which provides a contrast to the well-represented academic expertise on the team.

This student insight might challenge or validate the staff view, even though ultimately the staff must retain control of the project's outcomes. Bovill (2020) maintains that students are not on an equal footing in a co-creation project (e.g., the workshop consultations), drawing a major distinction between student-staff partnerships and cocreation. Bovill states that partnerships imply a joint relationship where staff and students share input equally and benefit equally, such as my involvement on the project team. However, in a co-creation process such as in the workshops, the relationship is, of necessity, 
skewed in favour of the staff as they ultimately have to ensure that any outcome is workable.

Therefore, my involvement on the project team was an example of a student-staff partnership with all members of the team on an equal footing. However, when I came to participate in the workshops as one of the students, I experienced the subordinate nature of a co-creation relationship with the workshop facilitators. I found it difficult to perform the subordinate role of a participating student in the workshop setting after experiencing the creative freedom of my equal status on the project team. Reconciling the two roles was awkward.

I began to see myself more suited to being a facilitator than a participant. Having been involved in the design of the project I was always conscious of the thinking behind each activity and task. In the workshop design meetings, team members, including myself, had tested out the various tasks and stages in order to see how well they provoked creative responses. When I came to be a participant in the workshop, I knew exactly what to expect, so there was no element of surprise or spontaneity. I found it difficult to put my experiences as a team member to one side.

\section{MY EXPERIENCE AS A STUDENT PARTICIPANT}

The students who participated in the workshops were, by their presence, enthusiastically behind the project. They saw it as a chance to contribute ideas which could evolve the way cognitive psychology was taught at the university. Students were set a series of tasks designed to make them think creatively about new ways the modules could be delivered. For example, there was an ideation task to come up with the "worst possible assignment," followed by a discussion about what makes a good assessment and brainstorming activities regarding group work. The students' viewpoints were summarised by the facilitators and then grouped under general themes (e.g., "student choice" and "variety"), and, together, participants chose one theme around which to design an assessment.

I struggled in the workshops as a participant. My prior involvement as a member of the project team kept dominating my contributions. I felt my knowledge of how the workshops had been designed gave me a biased view, instead of coming to the workshop fresh like the other student participants were able to. For example, one of the workshop design aims was to promote creative thinking and "outside-the-box" ideas rather than students merely stating their own personal preferences, saying "I like this..." or "I don't like that...". So when a student did get too specific, I found myself frustrated. It did not develop the workshop as the ideas factory that I had hoped for in the design process. I felt that I wanted to cut short my time as a student participant and instead help facilitators steer the workshop in my role as a team member, particularly since I was not able to experience the role of facilitator.

\section{LACK OF STUDENT ENGAGEMENT}

Student reluctance to engage in the process was an irritation for me at times during the project, especially when it adversely impacted on my opportunities within the project. I remember wishing that other students would take more interest in these initiatives. I felt the need to speak to some students who had not come forward in a bid to establish their reasons. Some saw the project as not affecting their university experience, as any changes made would be for the benefit of future students, which seemed selfish. Others did not fully 
understand what the project was trying to achieve, even though an introductory meeting to outline its aims was organised. The official post-workshop online survey of students and staff on the different psychology courses offered by the university revealed other reasons for non-participation. For the 20 students who responded, these reasons included time factors $(50 \%)$, lack of confidence in what they could contribute (25\%), and doubts that their contributions would be valued (15\%) or that their ideas would be implemented (15\%). To overcome the time issue, shorter workshops might be considered in the future.

Reassurances covering the other given reasons for non-participation could be made, but self-consciousness and a lack of self-belief in having valuable contributions to make are commonplace. The temptation often is to play safe and avoid any risk by not taking part. This reticence might be tackled in future by asking students who did take part in the workshops for their help in recruiting for future projects, sharing their experience and explaining participation from their perspective.

I believe another potential barrier to engagement could have been the idea of the student as consumer, where some students see their education as an example of goods and services they have ordered and paid for. Academic staff are expected to supply learning without students needing to do anything except listen. Students who see themselves in this consumer model reduce learning to a product instead of a process, a failing highlighted by McMillan and Cheney (1996).

The student-as-consumer view also reflects back to issues of power, notably the student's power to self-exclude. Students could regard refusing to participate as their way of displaying their power in the learning process. To participate could be seen by them as eroding their power; they go from a position of control (the power to self-exclude) to a subordinate role as a student participant with staff retaining the upper hand.

For whatever reason students declined to engage in the process, I believed these were the very people the project needed to reach and connect with. I felt we had to find a way to make these disengaged students lean forward to learn and to make them share responsibility for what they were being taught. I recognise that it takes a sizeable effort to move from the passivity of non-engagement to being an active learner, but I see this as one of the goals of student-staff collaborations. I wanted our co-creation project to give disaffected students who feel left out, ignored, or alienated an opportunity to have an active role in change. I was frustrated many students did not see this opportunity.

In conclusion, I feel that I gained more from my role as project team member than I did as student participant. I found the design process of the project, helping to oversee the workshops and analysing student input, more fulfilling. By comparison, although the role of student participant was obviously essential to the success of the project, I found it impossible to view other students' ideas except in the context of what I knew as someone who was invested in the project from its inception. I felt that my own ideas were almost certainly unconsciously influenced by my earlier work with the rest of the team. For optimum exchange of ideas, the student participants attending the workshops need to come to the table with an open mind and with no idea what to expect. I could not do that, and as a result my contribution as a participant was somewhat tainted. This is not to say that I did not learn a huge amount from performing each role. Both roles have great value, but combining the two did not work in my case. Although some might prefer to be involved in inputting ideas in the workshops, I preferred the teacher-led experiences of being on the project team where I, in my eyes, made a more important contribution. I would therefore question the value of combining two roles and urge focusing on one alone. 


\section{ACKNOWLEDGEMENTS}

The author wishes to thank the other project team members for their help and assistance in making this article possible: Dr Adam Galpin, Dr Catherine Thompson, Dr Simon Cassidy, Dr Robert C. A. Bendall, Dr Ben Short, Dr Maria Panagiotidi, and fellow student member Eileen Quigley. The project was funded by the Salford Community for Excellence in Learning and Teaching (SCELT).

\section{NOTE ON CONTRIBUTOR}

David Beevers is a PhD psychology student at the University of Salford in the UK, having graduated with a first-class BSC (Hons) degree in Psychology and Counselling Studies at the university in summer 2021. He returned to full-time education in 2018 after a long career in journalism. He has a particular interest in cognitive restoration.

\section{REFERENCES}

Bovill, C. (2020). Co-creation in learning and teaching: The case for a whole-class approach in higher education. Higher Education, 79(6), 1023-1037.

https://doi.org/10.1007/s10734-019-00453-w

Bridges, W. (2004). Transition: Making sense of life's changes: Strategies for coping with the difficult, painful and confusing times in your life (2nd ed.). Da Capo Press.

McMillan, J. J., \& Cheney, G. (1996). The student as consumer: The implications and limitations of a metaphor. Communication Education, 45(1), 1-15. https://doi.org/10.1080/03634529609379028

Murphy, R., Nixon, S., Brooman, S., \& Fearon, D. (2017). "I am wary of giving too much power to students:" Addressing the "but" in the principle of staff-student partnership. International Journal for Students as Partners, 1(1). https://doi.org/10.15173/ijsap.v1i1.3055 